\title{
Correlation between Mode of Delivery and Newborn's Cord Blood Composition
}

\author{
Abd El-Naser Abd El-Gaber Ali1 ${ }^{*}$, Ahmed Mustafa Mahmoud ${ }^{2}$ \\ ${ }^{1}$ Obstetrics \& Gynecology Department, Qena Faculty of Medicine, South Valley University, Qena, Egypt \\ ${ }^{2}$ Medical Physiology Department, Faculty of Medicine, Sohag University, Sohag, Egypt \\ Email: *abdelnaser.abdelgaber@med.svu.edu.eg
}

How to cite this paper: Abd El-Gaber Ali, A.E.-N. and Mahmoud, A.M. (2019) Correlation between Mode of Delivery and Newborn's Cord Blood Composition. Open Journal of Obstetrics and Gynecology, 9, 395-403.

https://doi.org/10.4236/ojog.2019.93040

Received: February 27, 2019

Accepted: March 17, 2019

Published: March 20, 2019

Copyright $\odot 2019$ by author(s) and Scientific Research Publishing Inc. This work is licensed under the Creative Commons Attribution International License (CC BY 4.0).

http://creativecommons.org/licenses/by/4.0/

\begin{abstract}
OBJECTIVE: The aim of this study is to find out the effect of delivery mode on newborn's cord blood parameters particularly hemoglobin and hematocrite values. SETTING: Obstetrics and Gynecology Department, Qena Faculty of Medicine, South Valley University, Egypt. DURATION: From April 2015 to December 2017. STUDY DESIGN: A cross sectional study. METHODS: 900 live born neonates for healthy mothers were included in this study; all cases were delivered at full-term, with birth weight ranged from 2.5 to $3.5 \mathrm{Kg}$ and had APGAR scores above 7 at 1 and 5 minutes. Newborns were divided into three groups (Group I included 300 newborns delivered by vaginal delivery without augmentation of labor, Group II included 300 newborns delivered vaginally with augmentation of labor and Group III included 300 newborns delivered by elective cesarean section). Blood sample was collected from the umbilical vein of each neonate for estimation of hemoglobin, hematocrit, RBCs count, platelets, WBCs count and reticulocytes. RESULTS: Cesarean section delivery had a statistically significant decrease in the level of iron-related hematologic indices including hemoglobin, hematocrit and RBCs count ( $\mathrm{p}$ value $<0.001)$. There was a statistically significant difference among studied groups in reticulocyte count with $(\mathrm{P}$ value $<0.05)$. There was a positive correlation among newborns cord blood hemoglobin as regard to head circumference, length and gestational age and negative correlations as regard to maternal age, parity and birth weight with no statistically significance $(\mathrm{P}$ value $>0.05$ ). CONCLUSIONS: Cesarean section delivery had a significant decrease in the level of iron-related hematologic indices including hemoglobin, hematocrit and RBCs count and has a non-significant decrease in WBCs and platelets counts in neonatal cord blood, which suggest high prevalence of newborn iron-deficiency anemia among cesarean births particularly in developing communities.
\end{abstract}




\section{Keywords}

Correlation, Mode of Delivery, Newborn, Cord Blood Composition

\section{Introduction}

Iron deficiency anemia usually affects both physical and mental development of children which is more prevalent in the developing countries (in 2005, prevalence of anemia in children $<4$ years old was $30 \%$ ). Placental perfusion reduction at time of birth was suggested to increase the risk of early life iron deficiency anemia [1]. Immediately post-delivery, the newborn's hemoglobin and hematocrit values increase about $10 \%$ during the first $6-8$ hours of early neonatal life; these enhancements are due to increase in the placental perfusion which occurs at birth time [2]. Newborns who were born through vaginal route generally had higher red blood cell count, haemoglobin $(\mathrm{Hb})$ level and haematocrit value comparable with those who were delivered by elective caesarean section (ECs). The delivery mode also affects the white blood cell (WBCs) count as neonates who were delivered vaginally had higher white blood cells and band counts comparable with newborns that were delivered by elective caesarean section [3]. It had been recognized that, uterine contractions could diminish utero-placental circulation while the circulation of healthy fetus with uncomplicated delivery remained unaffected. The umbilical cord circulation is relatively not reactive and does not respond to the changes that occur in the maternal placental blood flow during uterine contractions [4]. Augmented normal vaginal delivery depends on the infusion rate of augmented drugs, patient sensitivity to oxytocin and uterine response. Intense and/or frequent uterine contractions may be associated with decreased placental bed blood flow [5]. Cesarean section in comparison with vaginal delivery is usually associated with a reduction in placental perfusion and so poor iron-related hematologic indices in the cord and peripheral blood, which indicates that, neonates who delivered by cesarean section may be more likely to develop iron-deficiency anemia in infanthood [3]. The reducing effect of cesarean section (cs) on placental blood flow is due to the weaker transfusion force and due to the shorter transfusion period. A newborn delivered by cesarean section is usually put on the mother's abdomen after delivery; therefore, this position is higher than the placenta position before clamping and cutting the cord, which can prevent blood flowing from the placenta to newborn through umbilical cord due to a gravity act [6]. In fact in the last decade there was an increase in the cesarean delivery rate which synchronously was associated with an increase in the prevalence of infant anemia in developing countries particularly in our communities so we assigned this study to give alarm to obstetricians to stop unnecessary cesarean delivery and to encourage for vaginal delivery.

\section{Aim of Work}

The aim of this study is to find out mode of delivery effect on newborn's cord 
blood parameters particularly hemoglobin and hematocrite values.

\section{Methodology}

This is a cross sectional study was conducted on 960 pregnant women from attendants of delivery ward of obstetrics and gynecology department of South Valley University Hospital from April 2015 to December 2017. Good counselling associated with a well-formed written consent was obtained from each pregnant women participated in this study according to the Medical Ethics Committee of Qena faculty of medicine, south valley university. Sixty cases had been excluded from the study most of them delivered by elective cesarean section ( 5 cases had severe neonatal distress and needed immediate intubation and 55 newborns had low AGAR score $<7$ at 1 or 5 minutes). The study was applied on 900 live born neonates as they were divided into 3 groups according to the mode of delivery (Group I included 300 babies delivered with vaginal delivery without need for augmentation, Group II included 300 babies delivered vaginally with augmentation of labor by oxytocin infusion) and Group III included 300 babies delivered by planned cesarean section). Inclusion criteria (all babies were single living full term documented with accurate first date of last menstrual period or with report of first trimester ultrasound scanning, cephalic presentation in group I and II, birth weight ranged from 2.5 to $3.5 \mathrm{Kg}$ with APGAR score at 1 and 5 minutes > 7, maternal age 17 - 40 years old and only Rh positive mothers were included). Exclusion criteria (newborns with meconium stained amniotic fluid, $\mathrm{RH}$ or $\mathrm{ABO}$ incompatibility, congenital anomalies of newborns, newborns of diabetic mothers of any type, intrauterine growth restriction-mothers with any degree of anemia, mothers with any medical disorders, presence of high risk pregnancy as preeclampsia or any maternal blood diseases). Full history was taken from all women participated in this study with general, obstetric and local examination with routine laboratory investigations. Fetal ultrasound was done for all pregnant women before delivery to assess fetal biometry, estimated fetal weight, fetal presentation, position, placental location and assessment its maturity and assessment of amniotic fluid index. A continuous fetal monitoring was a tool for fetal monitoring in cases had chance for vaginal delivery (group I and group II).

Methods: 2 milliliter of peripheral venous blood sample was collected from each pregnant women for hemoglobin level assessment and blood grouping just before delivery and 2 milliliter of cord blood was collected immediately after delivery of placenta. Clamping of umbilical cord was done as early as possible within 30 second post-delivery), stripping of the cord was prohibited, as the baby was held at same mother level. Blood had collected from umbilical vein in a double clamped portion of the umbilical cord in a $3 \mathrm{~cm}$ sterilized syringe and collected in EDTA collecting tubes then samples were analyzed for blood groups, $\mathrm{Rh}$, reticuloctic count and complete blood count (CBC) for assessment of hematocrit value, hemoglobin level and RBCs, $\mathrm{MCH}, \mathrm{MCV}$, platelets, WBCs, neotrophil and lymphocytes. Maternal and newborns cord blood were analyzed on the 
same day of collection. Standard cyanmethemoglobin technique (PATH, 1996) was used for maternal hemoglobin evaluation and newborn complete blood picture analysis was done by using an Abbott Cell-Dyn 1700 automatic analyzer. Blood grouping was manually done using blood grouping reagents (anti A, anti $B$ and anti D). Also reticulocytes counting was done manually by the conventional microscope using supra vital stain. Anthropometric assessments of the newborns included birth weight, baby length and the head circumference. The birth weight was obtained by using the Salter spring balance to the nearest 20 grams. The newborn length and head circumference were measured by using (Pedobaby Baby meter to the nearest 0.1).

\section{Statistical Methods}

Statistical analysis was performed with the aid of the SPSS computer program (version 16 windows). Differences in quantitative variables mean between the three study groups were tested by using Three-way analysis of variance (ANOVA). All data was expressed as mean \pm S.D correlation between quantitative variables were tested by using Pearson correlation. A probability value of $\mathrm{p}<$ 0.05 indicates statistical significance.

\section{Results}

This study included 900 newborns male: female was 480:420. Table 1 had showed no statistically significant difference among mothers in the 3 studied groups as regard to maternal age, BMI, parity, hemoglobin level, systolic and diastolic blood pressure at time of delivery with $\mathrm{p}$ value $>0.05$. There were no statistically significant differences among the 3 studied groups as regard to newborns gestational age at time of delivery, Apgar score at one and five minutes, birth weight, baby length and head circumference with $\mathrm{p}$ value $>0.05$ (Table 2). Cesarean section delivery had a statistically significant decline in the iron-related hematologic indices level in comparison to the other 2 groups as Mean \pm SD of hemoglobin level was $(15.34 \pm 1.04,14.76 \pm 1.27$ and $13.54 \pm 1.13$ in groups I, II and III respectively), Mean \pm SD of hematocrit value was (47.02 $\pm 3.86,45.23 \pm$ 3.93 and $41.37 \pm 3.65$ in groups I, II and III respectively) and Mean \pm SD of RBCs count was $(4.56 \pm 0.45,4.37 \pm 0.45$ and $3.89 \pm 0.36$ in groups I, II and III respectively) with $\mathrm{p}$ value $<0.001$ but had no statistically significant differences in white blood cells (WBCs) and platelets counts with $\mathrm{p}$ value $>0.05$.There was a mildly statistically significant difference in reticulocyte count between two vaginal groups (Group I and group II) with P value $<0.05$ as the vaginal group with labor augmentation had reticulocyte count higher than vaginal group without augmentation, but there was no a statistically significant difference between vaginal and elective cesarean section group with $\mathrm{P}$ value $>0.05$ (Table 3 ). In this study there was positive correlations among newborns cord blood hemoglobin as regard to head circumference, length and gestational age, and there was negative correlations as regard to maternal age, parity and birth weight but statistically insignificant with $\mathrm{P}>0.05$ (Table 4). As regard to newborns gender 
and cord blood hemoglobin there were no statistically significant differences among studied groups $\mathrm{p}$ value $>0.05$ (Figure 1).

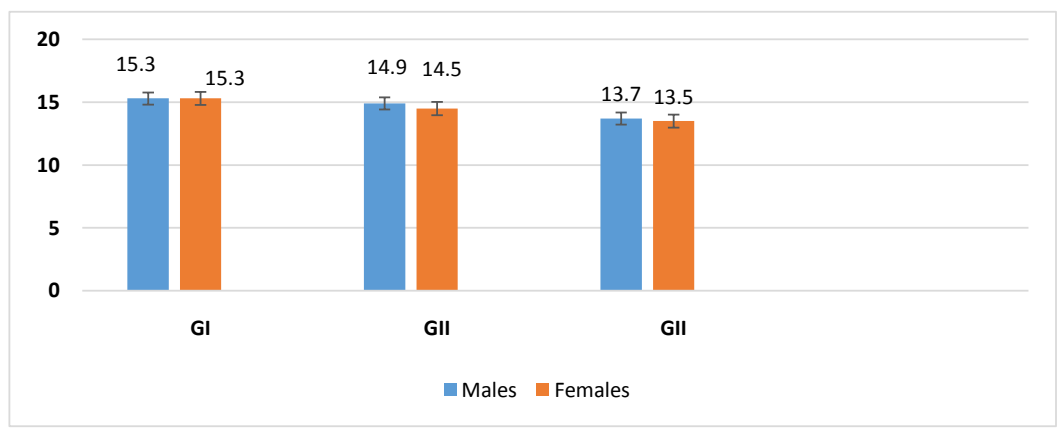

Figure 1. Correlation between newborn's gender and HB in studied group. Non-significant $\mathrm{p}$ value $>0.05$.

Table 1. Descriptive statistics of maternal demographic and biochemical data in the 3 studied groups.

\begin{tabular}{ccccc}
\hline & $\begin{array}{c}\text { Group I } \\
\text { No }=300\end{array}$ & $\begin{array}{c}\text { Group II } \\
\text { N0 }=300\end{array}$ & $\begin{array}{c}\text { Group III } \\
\text { N0 }=300\end{array}$ & $\begin{array}{c}\text { P } \\
\text { value }\end{array}$ \\
\cline { 2 - 4 } & Mean \pm SD & Mean \pm SD & Mean \pm SD & \\
\hline Maternal age in years & $26.2 \pm 4.5$ & $25.0 \pm 3.6$ & $27.0 \pm 4.40$ & 0.109 \\
BMI in kg/m ${ }^{2}$ & $24.7 \pm 1.1$ & $23.5 \pm 0.9$ & $25.8 \pm 1.2$ & 0.154 \\
Parity & $1.7 \pm 1.2$ & $1.4 \pm 1.6$ & $1.7 \pm 0.86$ & 0.384 \\
Blood pressure in mmHg & & & & 0.081 \\
Systolic & $112 \pm 8.4$ & $110 \pm 7.2$ & $114 \pm 7.2$ & 0.074 \\
Diastolic & $75 \pm 6.7$ & $75 \pm 6.2$ & $73 \pm 6.4$ & 0.321 \\
\hline
\end{tabular}

Non significance $(\mathrm{P}$ value $>0.05)$.

Table 2. Newborn gender, Gestational Age at time of delivery, Apgar score at one and five minutes, length, head circumference and birth weight in the 3 studied groups.

\begin{tabular}{|c|c|c|c|c|}
\hline & Group I & Group II & Group III & \multirow{2}{*}{$P$ value } \\
\hline & $\mathrm{N}=300$ & $\mathrm{~N}=300$ & $\mathrm{~N}=300$ & \\
\hline \multirow{2}{*}{$\begin{array}{c}\text { Gender No (\%) } \\
\text { Male } \\
\text { Female }\end{array}$} & $180(60.0)$ & $160(53.3)$ & $140(46.7)$ & Total 480 \\
\hline & $120(40.0)$ & $140(46.7)$ & $160(53.3)$ & Total 420 \\
\hline $\begin{array}{c}\text { Gestational age in weeks } \\
\text { Mean } \pm \text { SD }\end{array}$ & $37.87 \pm 0.43$ & $38.34 \pm 0.89$ & $37.97 \pm 0.65$ & 0.052 \\
\hline $\begin{array}{c}\text { Apgar score } \\
\text { At } 1 \text { min Median (range) } \\
\text { At } 5 \text { min Median (range) }\end{array}$ & $\begin{array}{c}90(8-10) \\
100(9-10)\end{array}$ & $\begin{array}{c}90(8-10) \\
100(9-10)\end{array}$ & $\begin{array}{l}80(7-10) \\
90(9-10)\end{array}$ & 0.731 \\
\hline $\begin{array}{c}\text { Birth weight in gram } \\
\text { Mean } \pm S D\end{array}$ & $2998.3 \pm 342.2$ & $2973.2 \pm 213.6$ & $3083.8 \pm 480.8$ & 0.443 \\
\hline $\begin{array}{l}\text { Head Circumference in } \mathrm{cm} \\
\qquad \text { Mean } \pm \mathrm{SD}\end{array}$ & $34.5 \pm 0.31$ & $33.7 \pm 0.24$ & $34 \pm 0.21$ & 0.951 \\
\hline $\begin{array}{c}\text { Baby Length in } \mathbf{c m} \\
\text { Mean } \pm \mathrm{SD}\end{array}$ & $50 \pm 0.53$ & $52 \pm 0.83$ & $51 \pm 0.36$ & 0.681 \\
\hline
\end{tabular}

Non-significant $\mathrm{p}$ value $>0.05$. 
Table 3. Cord blood hemoglobin, hematocrit, RBSs, WBCs and platelets count in the 3 studied groups.

\begin{tabular}{|c|c|c|c|c|}
\hline & Group I & Group II & Group III & \multirow{2}{*}{$P$ value } \\
\hline & $\mathrm{N}=300$ & $\mathrm{~N}=300$ & $\mathrm{~N}=300$ & \\
\hline Hematocrit $\%$ Mean \pm SD & $47.02 \pm 3.86$ & $45.23 \pm 3.93$ & $41.37 \pm 3.65$ & $0.001^{* *}$ \\
\hline $\begin{array}{c}\text { Hemoglobin in gm/dl } \\
\text { Mean } \pm \mathrm{SD}\end{array}$ & $15.34 \pm 1.04$ & $14.76 \pm 1.27$ & $13.54 \pm 1.13$ & $0.001^{* *}$ \\
\hline \multicolumn{5}{|l|}{ RBSs count in millions $/ \mathrm{cmm}$} \\
\hline mean \pm SD & $4.56 \pm 0.45$ & $4.37 \pm 0.45$ & $3.89 \pm 0.36$ & $0.001^{\star *}$ \\
\hline $\mathrm{MCV}$ mean $\pm \mathrm{SD}$ & $105 \pm 5.3$ & $103 \pm 5.9$ & $102 \pm 4.9$ & 0.097 \\
\hline $\mathrm{MCH}$ mean $\pm \mathrm{SD}$ & $34.5 \pm 2.0$ & $33.5 \pm 2.3$ & $33.2 \pm 1.25$ & 0.069 \\
\hline $\begin{array}{l}\text { Reticulocytes count } \\
\text { in millions } / \mathrm{cmm}\end{array}$ & $0.28 \pm 0.1$ & $0.41 \pm 0.2$ & $0.34 \pm 0.2$ & $0.033^{*}$ \\
\hline \multicolumn{5}{|l|}{ WBCs count millions $/ \mathrm{cmm}$} \\
\hline Mean \pm SD & $12 \pm 2.8$ & $12 \pm 3.5$ & $10.6 \pm 2.6$ & 0.153 \\
\hline Neutrophils (\%) & $50.5 \pm 7.4$ & $50 \pm 6.5$ & $46.9 \pm 10.3$ & 0.222 \\
\hline Lymphocyte (\%) & $38.2 \pm 7.4$ & $37.5 \pm 6.6$ & $41.4 \pm 10.7$ & 0.166 \\
\hline \multicolumn{5}{|l|}{$\begin{array}{l}\text { Platelets count in } \\
\text { millions } / \mathrm{cmm}\end{array}$} \\
\hline
\end{tabular}

* Mildly significant ${ }^{* *}$ highly significant.

Table 4. Correlation between newborns birth weight, head circumference, baby length, gestational age, maternal age, maternal parity and cord blood hemoglobin.

\begin{tabular}{ccc}
\hline & \multicolumn{2}{c}{ Hemoglobin } \\
\cline { 2 - 3 } & $\mathrm{r}$ & P value \\
\hline Birth weight & -0.013 & 0.907 \\
Baby Length & 0.015 & 0.491 \\
Head circumference & 0.013 & 0.839 \\
Gestational age & 0.183 & 0.085 \\
parity & -0.186 & 0.080 \\
Maternal age & -0.123 & 0.246 \\
\hline
\end{tabular}

$\mathrm{r}$ value represents Pearson correlation coefficient, Non-significant $\mathrm{p}$ value $>0.05$.

\section{Discussion}

Although there were marked advances in the perineonatology in the last decade, but actual influence of the perinatal factors on the haematological measures in newborn cord blood is still not fully understood. Many studies had been described the changes in the umbilical haematological parameters in newborn cord blood in the complicated pregnancy and in the abnormal labor, however there is inadequate data could be available explaining how the perinatal factors influence on the values of the cord blood in normal pregnancies with normal labor process [7]. Knowing the normal hematologic values of neonates, infants and early childhood seems to be essential for proper interpretation of the test results and 
for understanding the dynamic changes that occur during these periods. As regard to neonatal period, red blood cells (CBCs) could be highly correlated with the gestational age, the newborn birth weight, the site of blood sampling, baby crying, and the physical therapy [8]. This study showed, newborn's cord blood hemoglobin \& hematocrit values and red blood cells count in group III (Cesarean section group) were significantly lower than those in groups I and II (vaginal delivery groups, non-augmented group and augmented group) these results agreed with what had been reported by Fady et al. [9], this may be attributed to, that cesarean section is usually associated with reduced placental perfusion and decreased in the level of iron-related hematologic parameters include hemoglobin and hematocrit values in both cord and newborn's peripheral blood [3]. The reducing effect of cesarean section (Cs) on placental blood flow is due to the weaker perfusion force and the shorter perfusion period. As regard to cesarean section, a newborn usually be placed toward the mother's abdomen post-delivery so the newborn's position being at a high level in relation to the placenta location just prior to clamping and cutting the umbilical cord, that may likely prevent the cord blood flowing from placenta to newborn due to the effect of gravity [10]. Newborns delivered by elective cesarean section lack of uterine contractions in comparison with those delivered vaginally whether with augmented labor or not, as uterine contractions squeeze newborns' lung and so lung fluid no more persist post-delivery, as persistence of lung fluid may delay the onset of natural respiration and impede placental transfusion [6]. This study showed no statistically significant decrease in white blood cells (WBCs) and platelets counts in newborns' cord blood sample but showed a mildly statistically significant difference in the reticulocyte count between the group I and group II (vaginal groups; augmented and non-augmented), where the augmented vaginal group showed reticulocyte count higher than spontaneous vaginal group, in the other hand no statistically significant difference was found between vaginal and cesarean section group in reticulocyte count (Table 3) which may explained as that augmented group exposed to more hypoxia and stress due to more contractions. In this study there were no statistically significant differences in hemoglobin level for newborns' cord blood as regard to newborns' sex which agreed with a study reported by Jopling et al., [11] and Jasim et al., [12] but not agreed the results that had been reported by Mamoury et al., [13]. In this study we found positive correlations among newborns' cord blood hemoglobin as regard to head circumference, newborn length, fetal gestational age but we found a negative correlation among newborns of the three studied groups as regard to birth weight (Table 4). This study revealed that maternal age had no influence on cord blood hemoglobin level of newborns, that agreed with Danish et al., [14] study. This study showed a negative correlation between parity and cord hemoglobin and that agreed with a study reported by Danish et al., [14].

\section{Conclusion}

Cesarean section delivery had been associated with decline in the level of 
iron-related hematologic parameters which include hemoglobin \& hematocrit values and red blood cells count, with insignificant decrease in WBCs and platelets counts in neonatal cord blood, which suggest high prevalence of newborn iron-deficiency anemia among babies delivered by cesarean section particularly in developing communities.

\section{Recommendation}

1) Vaginal delivery should be encouraged particularly in developing countries with using awareness programs for the young physicians and pregnant ladies.

2) Iron stores and hemoglobin level in infancy could be improved in newborns who are delivered by cesarean section if we just delay cord clamping at birth for few seconds.

3) Prevention of newborns anemia can be achieved with umbilical cord milking in elective cesarean delivery as a routine maneuver or in situations where delaying cord clamping is prohibited.

\section{Conflicts of Interest}

The authors declare no conflicts of interest regarding the publication of this paper.

\section{References}

[1] Lozoff, B. and Georgieff, M.K. (2006) Iron and Brain Development. Seminars in Pediatric Neurology, 13, 158-165. https://doi.org/10.1016/j.spen.2006.08.004

[2] Susan, N. and Sithembiso, V. (2013) Promoting Physiologic Transition at Birth: Re-Examining Resuscitation and the Timing of Cord Clamping. Seminars in Fetal and Neonatal Medicine, 18, 385-392. https://doi.org/10.1016/j.siny.2013.08.008

[3] Zhou, Y.B., Li, H.T., Zhu, L.P. and Liu, J.M. (2013) Impact of Caesarean Section on Placental Transfusion and Iron-Related Haematological Indices in Term Neonates: A Systematic Review and Meta-Analysis. Placenta, 95, 1-8.

[4] Maršál, K. (2016) Fetal and Placental Circulation during Labor Fetal and Neonatal Physiology. Fifth Edition, Chapter 59, 611-618.

[5] Lobo, M.F., Bastos, L.F., van Meurs, W.L. and Ayres-de-Campos, D. (2013) A Model for Educational Simulation of the Effect of Oxytocin on Uterine Contractions. Medical Engineering \& Physics, 35, 524-535. https://doi.org/10.1016/j.medengphy.2012.06.021

[6] Kakkilaya, V., Pramanik, A.K., Ibrahim, H. and Hussein, S. (2008) Effect of Placental Transfusion on the Blood Volume and Clinical Outcome of Infants Born by Cesarean Section. Clinics in Perinatology, 35, 561-570. https://doi.org/10.1016/j.clp.2008.07.002

[7] Redźko, S., Przepieść, J., Zak, J., Urban, J. and Wysocka, J. (2005) Influence of Perinatal Factors on Haematological Variables in Umbilical Cord Blood. Journal of Perinatal Medicine, 33, 42-45. https://doi.org/10.1515/JPM.2005.007

[8] Proytcheva, M.A. (2009) Issues in Neonatal Cellular Analysis. American Journal of Clinical Pathology, 95, 560-573. https://doi.org/10.1309/AJCPTHBJ4I4YGZQC

[9] El Gendya, F.M., Allamb, A.A., Allamc, M.M. and Allamd, R.K. (2016) Haemato- 
logical Parameters of Newborns Delivered Vaginally versus Caesarean Section. Menoufia Medical Journal, 29, 259-264. https://doi.org/10.4103/1110-2098.192429

[10] Shirvani, F., Radfar, M., Hashemieh, M., Soltanzadeh, M.H., Khaledi, H. and Mogadam, M.A. (2010) Effect of Timing of Umbilical Cord Clamp on Newborns' Iron Status and Its Relation to Delivery Type. Archives of Iranian Medicine, 13, 420-425.

[11] Jopling, J., Henry, E., Wiedmeier, S.E. and Christensen, R.D. (2009) Reference Ranges for Hematocrit and Blood Hemoglobin Concentration during the Neonatal Period: Data from a Multihospital Health Care System. Pediatric, 123, 333-337. https://doi.org/10.1542/peds.2008-2654

[12] Al-Marzoki, J.M., Al-Maaroof, Z.W. and Kadhum, A.H. (2012) Determination of Reference Ranges for Full Blood Count Parameters in Neonatal Cord Plasma in Hilla, Babil. Journal of Blood Medicine, 3, 113-118.

[13] Mamoury, G.H., Hamedy, A.B. and Alkhlaghi, F. (2003) Cord Hemoglobin in Newborn in Correlation with Maternal Hemoglobin in Northeastern Iran. Iranian Journal of Medical Sciences, 28, 166-168.

[14] Danish, Q., Sandila, M.P., Kazmi, T. and Ahmed, S.T. (2009) Influence of Maternal Factors on Hematological Parameters of Healthy Newborns of Karachi. Pakistan Journal of Physiology, 5, 34-37. 